\title{
Synthesis and Characterization of New 3-Substituted Thiophene Copolymers
}

\author{
Marcos R. A. Alves, * Hállen D. R. Calado, Claudio L. Donnici and Tulio Matencio \\ Departamento de Quimica, ICEx, Universidade Federal de Minas Gerais, \\ 31270-901 Belo Horizonte-MG, Brazil
}

\begin{abstract}
Três polímeros e dois novos copolímeros baseados em derivados de politiofenos 3-substituídos têm sido estudados e todos demonstraram propriedades fotoluminescentes. Todos os polímeros sintetizados, poli(3-metoxitiofeno) (PMOT), poli(3-tiofenoetanol) (PTE), poli(3-tiofenometanol) (PTM), e copolímeros, poli(3-metoxitiofeno-co-3-tiofenoetanol) (PMOT-co-TE) e poli(3metoxitiofeno-co-3-tiofenometanol) (PMOT-co-TM), foram caracterizados por FT IR, UV-Vis, fotoluminescência (PL), análise térmica (TG e DSC) e difração de raios X. Todos os materiais mostraram emissão de luz na região do laranja do espectro visível. A obtenção dos polímeros e copolímeros foi confirmada por análise espectrométrica na região do infravermelho. A análise térmica mostrou boa estabilidade térmica para os materiais obtidos.
\end{abstract}

This work reports the synthesis of three polymers and two new copolymers based on 3 -substituted polythiophene derivatives, all of them demonstrated photoluminescent properties. All polymers synthesized, i.e., poly(3-methoxythiophene) (PMOT), poly(3-thiopheneethanol) (PTE), poly(3-thiophenemethanol) (PTM), poly(3-methoxythiophene-co-3-thiopheneethanol) (PMOT-co-TE) and poly(3-methoxythiophene-co-3-thiophenemethanol) (PMOT-co-TM), were characterized by FT IR, UV-Vis, photoluminescence (PL), thermal analysis (TG and DSC) and $\mathrm{X}$-ray diffraction (XRD). All materials emitted light in the orange region of the visible spectrum. Spectrometric analysis in the infrared region demonstrated the successful synthesis of polymers and copolymers by the presence of characteristic bands. Thermal analysis showed that the obtained materials had good thermal stability.

Keywords: conjugated polymer, copolymer, 3-substituted thiophene, photoluminescence

\section{Introduction}

Intrinsically conductive polymers obtained from thiophenes and their derivatives possess thermal and environmental stability ${ }^{1}$ as well as electronic and optical properties that enable applications such as organic transistors, ${ }^{1,2}$ anticorrosives, ${ }^{3,4}$ electrochromic materials ${ }^{5}$ and rechargeable batteries, ${ }^{6}$ leading to intense and increasing interest in these materials by research groups all over the world. The search for new technological materials has significantly contributed to the development of new precursors and synthetic methods that generate materials with desirable properties. ${ }^{7-10}$ These materials can be obtained by different polymerization methods, the most common of which employs ferric chloride as an oxidizing agent under an inert atmosphere, ${ }^{11-17}$ with other methods including electrochemistry techniques,

\footnotetext{
*e-mail: marcosrabreu@yahoo.com.br
}

such as cyclic voltammetry, ${ }^{18}$ chronoamperometry ${ }^{19,20}$ and chronopotentiometry. ${ }^{21}$ The electronic and optical properties of these polymers can be controlled using monomers that have functional groups incorporated into the structure that can contribute to the properties of the polymer chain; for example, poly(3-methoxythiophene) has been extensively studied due to the presence of oxygen in the alkoxy group, which decreases the oxidation potential of the monomer and polymer through its effects as an electron donor substituent. ${ }^{22-24}$ Other groups such as hydroxyl groups have been described as undesirable ones, because they can behave as nucleophiles, attacking the radical cations presented in the solution and leading to coupled compounds with low electric activity. ${ }^{25,26}$

The technique of copolymerization has been widely used as a way to obtain materials with properties intermediate between those of the individual homopolymers. ${ }^{27,28}$ Thus, the physical and chemical properties of the final material can be controlled through 
the appropriate choice of monomers that form the polymer chain. We previously studied the influence of alkoxy and hydroxyl groups on the formation and properties of their homopolymers and copolymers, and in this work we report the synthesis of the polymers poly(3methoxythiophene) (PMOT), poly(3-thiopheneethanol) (PTE), poly(3-thiophenemethanol) (PTM) (obtained previously only through electrochemical polymerization $)^{29}$ and two new copolymers: poly(3-methoxythiopheneco-3-thiopheneethanol) (PMOT-co-TE) and poly(3methoxy thiophene-co-3-thiophenemethanol) (PMOT-co-TM). Spectrometric measurements in the infrared region exhibited the expected bands, demonstrating the successful synthesis of polymers and copolymers. X-ray diffraction, gel permeation chromatography and thermal analysis were also carried out. Measurements of the absorption and emission of electromagnetic radiation by these materials suggest their potentiality for application in electroluminescent devices.

\section{Experimental}

\section{Materials}

The 3-methoxythiophene (98\%) (MOT), 3-thiophenemethanol (98\%) (TM), 3-thiopheneethanol (99\%) (TE) and ferric chloride (97\%) were obtained from Aldrich. All monomers were used without prior purification. The solvents chloroform (99.8\%), dimethylsulfoxide (DMSO) and $N, N$-dimethylformamide (DMF) were acquired from Synth.

Synthesis

Polymerizations and copolymerizations were carried out at room temperature under an inert atmosphere (nitrogen gas) by adapting the procedures described elsewhere. ${ }^{12,17,30}$

\section{Polymers}

Each monomer (MOT, TE or TM) $\left(0.05 \mathrm{~mol} \mathrm{~L}^{-1}\right)$ was dissolved in chloroform. A suspension of anhydrous $\mathrm{FeCl}_{3}$ (0.2 mol L $\left.{ }^{-1}\right)$, also in chloroform, was added to the flask with magnetic stirring at room temperature under an inert atmosphere (Scheme 1). The monomer solution was slowly dripped into the reaction flask over $30 \mathrm{~min}$. When the addition was complete, the reaction time was monitored by thin layer chromatography (TLC) using chloroform as the solvent and silica gel as the adsorbent. The end of the reaction was determined by the total consumption of monomer. The polymers poly(3-methoxythiophene)
(PMOT) and poly(3-thiophenemethanol) (PTM) were obtained after $2 \mathrm{~h}$ reaction. The poly(3-thiopheneethanol) (PTE) was obtained after $3 \mathrm{~h}$.

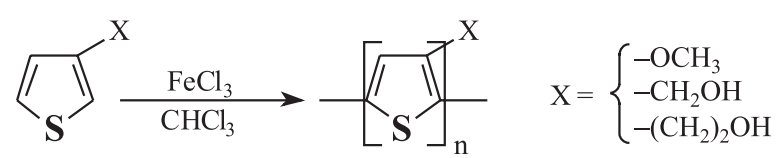

Scheme 1. Synthetic route of PMOT $\left(\mathrm{X}=-\mathrm{O}-\mathrm{CH}_{3}\right), \mathrm{PTE}\left(\mathrm{X}=-\left(\mathrm{CH}_{2}\right)_{2} \mathrm{OH}\right)$ and PTM $\left(\mathrm{X}=-\mathrm{CH}_{2} \mathrm{OH}\right)$.

\section{Copolymers}

Copolymers were obtained by the chemical copolymerization of monomers of TE and TM with the monomer MOT at a molar ratio of 2:1. A suspension of $\mathrm{FeCl}_{3}\left(0.2 \mathrm{~mol} \mathrm{~L}^{-1}\right)$ in chloroform was added to the flask with magnetic stirring at room temperature under an inert atmosphere. A solution of equal volume containing the two monomers (TE and MOT or TM and MOT) $\left(0.05 \mathrm{~mol} \mathrm{~L}^{-1}\right)$ was dripped slowly into the reaction flask over $30 \mathrm{~min}$ under magnetic stirring (Scheme 2). The reaction was monitored by TLC using chloroform, as the solvent, and silica gel, as the adsorbent. The end of the reaction was determined by the total consumption of monomer. The poly(3methoxythiophene-co-3-thiophenoethanol) (PMOT-co-TE) and poly(3-methoxythiophene-co-3-thiophenemethanol) (PMOT-co-TM) products were obtained after 4 and $2 \mathrm{~h}$ reaction, respectively.

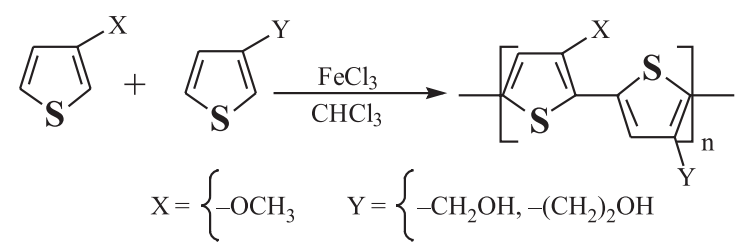

Scheme 2. Synthetic route of the copolymers PMOT-co-TE $\left(\mathrm{X}=-\mathrm{OCH}_{3}\right.$, $\left.\mathrm{Y}=-\left(\mathrm{CH}_{2}\right)_{2} \mathrm{OH}\right)$ and PMOT-co-TM $\left(\mathrm{X}=-\mathrm{OCH}_{3}, \mathrm{Y}=\mathrm{CH}_{2} \mathrm{OH}\right)$.

Polymers and copolymers were obtained in the form of dark powders, but the purified PTM appeared redishbrown at the end of the purification process (Figure S1, see Supplementary Information, SI, online). Before spectroscopic analysis, all the samples were submitted to purification to ensure the absence of residues of monomers and other reactants involved in the synthesis process. The PMOT was purified by stirring the polymer with five portions of $40 \mathrm{~mL}$ of diethyl ether. The polymers and copolymers PTE, PTM, PMOT-co-TE and PMOT-co-TM were purified by Soxhlet extraction with methanol. Importantly, the homopolymer PMOT is partially soluble in methanol and it disperses quite efficiently in this solvent (blue coloration in the solvent). Because of this, 
the purification was performed employing diethyl ether as a solvent. During the purification of polymers PTE and PTM and copolymers PMOT-co-TE and PMOT-co-TM, no solubilization or suspension it was observed using methanol as the solvent. The lack of a blue color in the solvent during the purification of the copolymers suggests either that the homopolymer PMOT it was not formed or those oligomers it was formed from the MOT, indicating that the blends were not formed during the copolymerization.

\section{Analyses}

Infrared spectra (FT IR) were recorded for all samples in powder form on a Nicolet 380 spectrometer by attenuated reflectance total (ATR). The thermal behavior of the mass loss (TGA) was investigated in a SDT 2960 simultaneous DTA TGA. Differential scanning calorimetry (DSC) curves for the polymers were obtained with a TA Instruments apparatus, model MTDSC 2920. Approximately $5 \mathrm{mg}$ of each sample was loaded in an aluminum pan, and the analysis was performed according to the following procedure: $i$ ) ramp heating at $10{ }^{\circ} \mathrm{C} \mathrm{min}^{-1}$; up to $110^{\circ} \mathrm{C}$ to dry residual volatiles, ii) isothermal holding for $1 \mathrm{~min}$, iii) quenching (inside the DSC cell) at a rate of $c a .10{ }^{\circ} \mathrm{C} \mathrm{min}^{-1}$ down to $-100{ }^{\circ} \mathrm{C}$, iv) isothermal holding for $3 \mathrm{~min}$, and $v$ ) ramp heating at $5{ }^{\circ} \mathrm{C} \mathrm{min}{ }^{-1}$ up to $150{ }^{\circ} \mathrm{C}$. Measurements were carried out using helium as a carrier gas at a flow rate of $50 \mathrm{~mL}$ $\mathrm{min}^{-1}$. Analysis of ultraviolet radiation (UV-Vis) was performed in DMF with a HITACHI UVSOLUTION 2010 spectrophotometer. Photoluminescence (PL) spectra of all samples were obtained in DMF at room temperature. The cuvette containing the solutions was mounted on top of an XY driver, which enabled us to move samples with small displacements without losing the optical alignment. A Q-switched Nd:YAG laser emitting at $488 \mathrm{~nm}$ was used as the excitation source. The PL emission was collected in a backscattering configuration and focused into an Ocean Optics USB2000 Miniature Fiber Optic Spectrometer. X-ray diffraction (XRD) measurements were obtained from samples in powder from on a Rigaku Geigerflex diffractometer with a cobalt (Co) tube, a voltage of $32.5 \mathrm{KV}$, a current of $25 \mathrm{~mA}$ and $2 \theta=5-60^{\circ}$. Gel permeation chromatography (GPC) was performed in a gel chromatography system model Shimadzu LC - 10 AD/CTA - 10 A GPC with a column Shim-Pack 803/804-D Shimadzu (Exclusion limit $\mathrm{M}_{\mathrm{w}} 7 \times 10^{4}$ and $\left.4 \times 10^{5}\right) 300 \times 7.8 \mathrm{~mm}$, a $20 \mu \mathrm{L}$ injection, a flow rate of $1.0 \mathrm{~mL} \mathrm{~min}{ }^{-1}$, UV-Vis detection at $300 \mathrm{~nm}$, polystyrene standards and DMF as the mobile phase.

\section{Results and Discussion}

The polymerization technique employed in this work provided polymers in good yields and it has the advantages of simplicity and a lack of unstable intermediates. PMOT has been obtained by other groups ${ }^{17,24}$ employing the oxidative method with $\mathrm{FeCl}_{3}$. Some authors ${ }^{23}$ have obtained PMOT after $24 \mathrm{~h}$ of reaction at room temperature, requiring the addition of methanol as a precipitating agent. Other researchers ${ }^{17}$ have shown that keeping the reaction temperature between $0-2{ }^{\circ} \mathrm{C}$ yields PMOT after $2 \mathrm{~h}$ reaction. The procedure described in this paper yielded PMOT after $2 \mathrm{~h}$ reaction at room temperature. This method is interesting because it allowed us to obtain all polymers and copolymers reported in this paper in a short period of time in the form of a powder at the bottom of the reaction system, without the requirement for any precipitating agent. PTE chemical synthesis was reported by Philip et al..${ }^{31}$ but their study focused on obtaining and characterizing the composite formed between the polymer (matrix) and carbon nanotubes (charge). The polymer yields in our study were 90\% (PMOT), 60\% (PTE), 77\% (PTM), 80\% (PMOT-coTE) and $71 \%$ (PMOT-co-TM).

The dissolution of these materials in DMF and in DMSO only was possible after employ magnetic stirring and bath ultrasonically over a period of eight days. In fact, PMOT have total solubilization of $1 \mathrm{mg}$ in $10 \mathrm{~mL}\left(0.1 \mathrm{mg} \mathrm{mL}^{-1}\right)$ of DMF or DMSO. For the polymer PTE and copolymers PMOT-co-TE and PMOTco-TM, $1 \mathrm{mg}$ by each of them can be solubilized in $60 \mathrm{~mL} \mathrm{DMF}\left(0.017 \mathrm{mg} \mathrm{mL}^{-1}\right)$ in Figure S1 (see SI). In DMSO, $0.017 \mathrm{mg} \mathrm{mL}^{-1}$ of the polymer PTE and copolymers PMOT-co-TE and PMOT-co-TM showed a smaller amount of suspended particles, but, we do not know yet how much soluble they are. The PTM is little soluble in both solvents and we observed a small solubilized fraction in both solvents (DMF and DMSO), almost everything stayed in the form of dispersion.

For GPC analyses the samples were dissolved in DMF. Table 1 shows the GPC results for polymers PMOT and PTE and copolymers PMOT-co-TE and PMOT-co-TM. The materials had a high weight average molar mass $\left(\overline{\mathrm{M}}_{\mathrm{w}}\right)$ between 207,300 and 279,300 $\mathrm{g} \mathrm{mol}^{-1}$ and a number weight average molar mass $\left(\overline{\mathrm{M}}_{\mathrm{n}}\right)$ between 150,000 and 233,000 $\mathrm{g} \mathrm{mol}^{-1}$. The polydispersity of these polymers were between 1.19 and 1.38. The result of GPC in DMF for solubilized fraction of PTM showed $\overline{\mathrm{M}}_{\mathrm{w}} c a .2,000$ that is characteristic of oligomers.

\section{Infrared characterization}

The spectra of both monomers and homopolymers can be found in Figures S2, S3 and S4 (see SI). Although the 
Table 1. Characteristic molecular weight of the polymers and copolymers

\begin{tabular}{lccc}
\hline Polymers & $\overline{\mathrm{M}}_{\mathrm{n}}$ & $\overline{\mathrm{M}}_{\mathrm{w}}$ & $\overline{\mathrm{M}}_{\mathrm{w}} / \overline{\mathrm{M}}_{\mathrm{n}}$ \\
\hline PMOT & 233,000 & 279,300 & 1.19 \\
PTE & 193,300 & 260,500 & 1.34 \\
PMOT-co-TE & 214,500 & 263,400 & 1.22 \\
PMOT-co-TM & 150,000 & 207,300 & 1.38 \\
\hline
\end{tabular}

PTM presented extremely low solubility in both solvents (DMF/SMSO), it is not possible to obtain GPC results.

bands found in the copolymers can also be found in the corresponding homopolymers, different interactions and vibrational couplings due to the presence of two monomers with different substituents result in the displacement of the copolymer bands when compared to the spectra of their respective homopolymers (Figure 1a). Thus, according to the region of "finger prints" of the spectra of copolymers and homopolymers (Figure 1b), and taking into account that consumption of the two monomers was observed by TLC during the process of copolymerization and that these materials were thoroughly purified, we conclude that the spectral differences between the copolymers and homopolymers are evidence of the formation of copolymers between the MOT and monomers TE and TM. Nevertheless, the following thermal analysis and UV-Vis results show that the copolymers exhibit properties intermediate between those of the homopolymers (expected behavior based on the literature), ${ }^{27}$ which proves that copolymerization was successful.

The infrared spectra for the polymers and copolymers in Figure 1 shows the expected characteristic bands. PMOT showed absorption bands at 2,930 and 2,873 $\mathrm{cm}^{-1}$ corresponding to the $\mathrm{C}-\mathrm{H}$ stretching of the $\mathrm{CH}_{3}$ group, demonstrating the presence of methoxy groups. Bands associated with the vibrational modes of the thiophene ring were found at $1,490,1,469$ and $1,434 \mathrm{~cm}^{-1}$. The band at $1,325 \mathrm{~cm}^{-1}$ is attributed to the angular deformation of $-\mathrm{C}-\mathrm{H}$. The stretching of the $\mathrm{C}_{\text {(ring) }}-\mathrm{O}-\mathrm{C}$ group has been identified as the band at $1,057 \mathrm{~cm}^{-1}$. Bands corresponding to the angular deformation out of the plane of the thiophene ring can be found at $856-701 \mathrm{~cm}^{-1}$.

PTE and PTM present infrared spectra with bands at 3,259 and $3,417 \mathrm{~cm}^{-1}$, respectively, corresponding to the stretching of the hydroxyl group. A shoulder is observed at 3,058 (PTE) and 3,099 $\mathrm{cm}^{-1}$ (PTM), corresponding to the $=\mathrm{C}-\mathrm{H}$ stretching of the thiophene ring. Bands at 2,925 and $2,872 \mathrm{~cm}^{-1}$ for PTE and 2,965 and 2,895 $\mathrm{cm}^{-1}$ for PTM correspond to the stretching of the $-\mathrm{CH}_{2}-$ group. Bands associated with the vibrational modes of the thiophene ring were found at 1,511 (PTE) and 1,507 $\mathrm{cm}^{-1}$ (PTM). Bands associated with the angular deformation of $-\mathrm{C}-\mathrm{H}$ are found
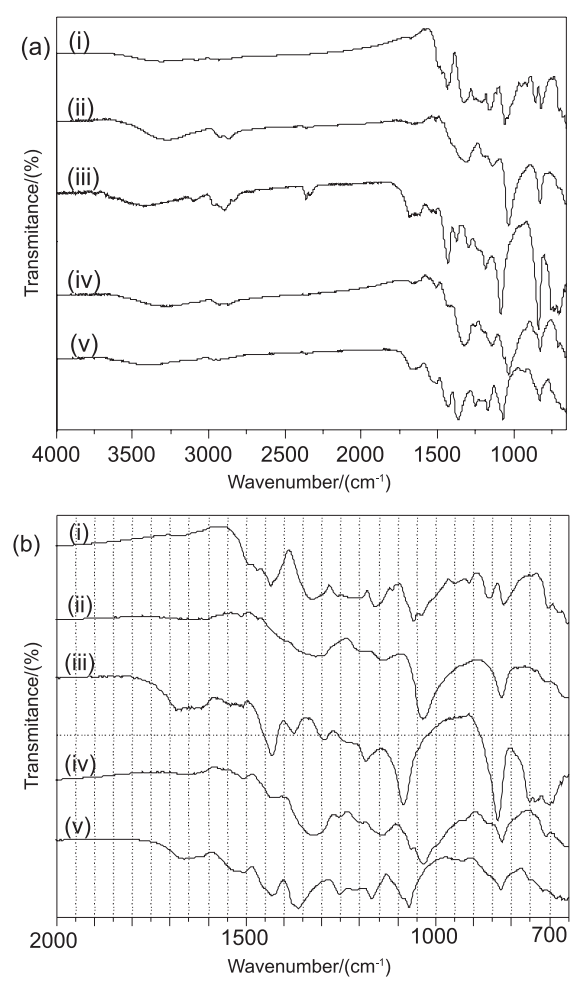

Figure 1. FT-IR spectra of polymers and copolymers: (i) PMOT, (ii) PTE, (iii) PTM, (iv) PMOT-co-TE and (v) PMOT-co-TM.

at 1,315 (PTE) and $1,374 \mathrm{~cm}^{-1}$ (PTM). Stretching of the $\mathrm{C}-\mathrm{O}$ group is associated with the band at 1,032 (PTE) and $1,083 \mathrm{~cm}^{-1}(\mathrm{PTM})$. The band corresponding to the angular deformation out of the plane of the thiophene ring can be found at 826 (PTE) and $836-736 \mathrm{~cm}^{-1}$ (PTM).

The copolymers PMOT-co-PTE and PMOT-co-TM showed absorption bands at 3,271 and $3,413 \mathrm{~cm}^{-1}$, respectively, corresponding to the stretching of the hydroxyl group. The bands at 3,080 (PMOT-co-TE) and 3,104 $\mathrm{cm}^{-1}$ (PMOT-co-TM) are due to the $=\mathrm{CH}$ stretching. The bands at 1,324 (PMOT-co-TE) and $1,362 \mathrm{~cm}^{-1}$ (PMOT-co-TM) are assigned to the angular deformations of $-\mathrm{C}-\mathrm{H}$. The stretching of the $\mathrm{C}-\mathrm{O}$ group was observed as bands at 1,032, 1,062 (PMOT-co-TE) and 1,069 $\mathrm{cm}^{-1}$ (PMOT-co-TM). Bands corresponding to the angular deformation out of the plane of the thiophene ring can be found between $825-707 \mathrm{~cm}^{-1}$ (PMOT-co-TE) and $827-715 \mathrm{~cm}^{-1}$ (PMOT-co-TM).

The IR spectra obtained for the prepared polymers and copolymers showed enlargement and displacement of the bands and the disappearance of some bands when compared to the IR spectra of the corresponding monomers. The band observed around $1,670 \mathrm{~cm}^{-1}$ can be attributed to the couplings associated with the attack by the hydroxyl group of the side chain of monomers TE and TM to the cation radical that occurs during the polymerization process. Pohjakallio et al., ${ }^{32}$ associate this band to the formation of a carbonyl group with a positive charge concentrated 
on oxygen atom 32 (this positive charge is due to the fact that the polymers and copolymers were obtained in their oxidized forms).

In the homopolymers PTE and PTM, beyond the band related to the hydroxyl group, there is a band corresponding to stretching between $\mathrm{C}-\mathrm{O}$ in 1,032 (PTE) and $1,083 \mathrm{~cm}^{-1}$ (PTM). For PMOT ${ }^{22}$, a stretch $\mathrm{C}_{\text {(ring) }}-\mathrm{O}-\mathrm{C}$ appears at $1,057 \mathrm{~cm}^{-1}$. For the copolymers, two peaks are observed in the same region due to the presence of groups $\mathrm{C}_{\text {(ring) }}-\mathrm{O}-\mathrm{C},-\mathrm{CH}_{2} \mathrm{OH}$ (PMOT-co-TM) and $\mathrm{CH}_{2}-\mathrm{CH}_{2}-\mathrm{OH}$ (PMOT-co-TE). In the copolymer PMOT-co-TE, the sharp band at $1,062 \mathrm{~cm}^{-1}$ can be attributed to the methoxy group from monomer MOT in the polymer chain, and the other sharp band at $1,032 \mathrm{~cm}^{-1}$ is assigned to the group $\mathrm{CH}_{2}-\mathrm{CH}_{2}-\mathrm{OH}$ (from monomer TE). For the copolymer PMOT-co-TM, a band is observed at $1,069 \mathrm{~cm}^{-1}$ (attributed to the methoxy group) and a shoulder is observed at $1,083 \mathrm{~cm}^{-1}$ (corresponding to the monomer TM).

\section{Thermal analysis (TG and DSC)}

Figure 2 shows the TG and DTG profiles for the polymers and copolymers. All materials have different behaviors as evidenced by the DTG curves in the temperature range of 33-990 ${ }^{\circ} \mathrm{C}$. PMOT (Figure 2a) loses mass in four steps: the first one $\left(145-270^{\circ} \mathrm{C}\right)$ may be related to the loss of the alkoxy ${ }^{21}$ group, and the steps afterwards (270-726 ${ }^{\circ} \mathrm{C}$ ) to weight loss due to the degradation of the polymeric chain, with a residual mass equal to $32 \%$. PTE (Figure 2b) remained stable up to $200^{\circ} \mathrm{C}$, with weight loss occurring beyond this temperature in steps distinct from those of PMOT. The first step, $200-313^{\circ} \mathrm{C}$, had a maximum rate of mass loss at $304^{\circ} \mathrm{C}$. PTM (Figure 2c) was stable up to $230{ }^{\circ} \mathrm{C}$, with weight loss in one step $\left(230-507^{\circ} \mathrm{C}\right)$, with a maximum rate of mass loss at $402{ }^{\circ} \mathrm{C}$. The difference between the thermal stability observed between PTE and PTM may be related to the large size of the side chains in PTE that could decrease the thermal stability of the polymer, as reported for poly(3-alkylthiophene) and poly(3alkoxythiophenes). ${ }^{22,33}$ The copolymer PMOT-co-TE (Figure 2d) was thermally stable up to $175^{\circ} \mathrm{C}$ and then lost weight in three steps. The first step $\left(175-321^{\circ} \mathrm{C}\right)$ involved a weight loss of $30 \%$, which may be associated with the loss of the side chains $-\mathrm{O}-\mathrm{CH}_{3}$ and $-\mathrm{CH}_{2}-\mathrm{CH}_{2}-\mathrm{OH}$. The second mass loss may be related to the degradation of the chain of the copolymer. The copolymer PMOT-co-TM (Figure 2e) was thermally stable up to $200{ }^{\circ} \mathrm{C}$, with mass loss then occurring in two steps. Comparing the two copolymers, their behavior is similar to that of their individual polymers (PTE and PTM), with improved thermal stability over PMOT.
Figure 3 and Table 2 show the DSC results. None of these samples presented DSC signals associated with melting. PTE undergoes a vitreous transition at a $\mathrm{T}_{\mathrm{g}}$ of $48{ }^{\circ} \mathrm{C}$, and PTM at $41{ }^{\circ} \mathrm{C}$. According to the literature, ${ }^{\frac{g}{22}}$ if only the size of the substituent group influenced the $\mathrm{T}_{\mathrm{g}}$, PTM would display a higher $\mathrm{T}_{\mathrm{g}}$ than PTE, but in the case of these samples, the extent of conjugation apparently has a greater influence than the size of the lateral chains, that present sizes differing from of a single $\mathrm{CH}_{2}$ group. These $\mathrm{T}_{\mathrm{g}}$ values also suggest that PTE may have a greater number of hydroxyl groups, resulting in a greater amount of hydrogen bonds compared to PTM and causing the increase in the energy required to weaken these intermolecular interactions. The results obtained from UV-Vis analysis agree with this explanation, as they showed less conjugation for PTM (red shift), which may be related to an increasing amount of coupling caused by attacks from hydroxyl groups in the cation-radical during polymerization.

Copolymers PMOT-co-TE and PMOT-co-TM had $\mathrm{T}_{\mathrm{g}}$ values at 56 and $59{ }^{\circ} \mathrm{C}$, respectively. These materials behave as expected, ${ }^{22}$ with $\mathrm{T}_{g}$ values between those of their individual homopolymers. The values close of the $\mathrm{T}_{\mathrm{g}}$ between PMOT-co-TE and PMOT-co-TM and higher than the values observed for PTM and PTE homopolymers demonstrate the contribution of PMOT to $\mathrm{T}_{\mathrm{g}}$. In the synthesis of PMOT-co-TM, the monomer MOT influenced the form in which the TM coupled, disfavoring couplings caused by the attack by hydroxyl groups in cation radicals during the polymerization process. This observation is based on two factors: first, the $T_{g}$ of this material is greater than that of PMOT-co-TE, and second, the red shift of $\lambda_{\max }$ observed by UV-Vis measurements was greater for PMOTco-TM than for PTM, indicating that the coupling between the monomers MOT and TM likely have fewer couplings formed by attacks by hydroxyl groups in cation radicals.

\section{$X$-ray diffraction}

Figure 4 shows the X-ray diffratograms obtained. All polymers and copolymers presented a broad and diffuse peak, indicating that the samples are not crystalline materials. This is in accordance with DSC analysis. All samples reach their maximum intensity at $2 \theta=26-31^{\circ}$. The presence of an amorphous structure can be attributed to the formation of cross-links (1,3-couplings) between thiophene rings. ${ }^{11}$

\section{Optical characterization}

Table 3 shows a summary of data obtained from absorption (UV-Vis) and photoluminescence (PL) 



Figure 2. TG-DTG curves of the polymers and copolymers: (a) PMOT; (b) PTE; (c) PTM; (d) PMOT-co-TE; and (e) PMOT-co-TM.

measurements. Figure 5 shows the absorption spectra for the sample solutions. Bands for the homopolymers and copolymers were observed in same range between 400-500 nm. PMOT showed an absorption band at $452 \mathrm{~nm}(2.75 \mathrm{eV})$, in agreement with data provided in the literature ${ }^{22}$ for this material $(475-430 \mathrm{~nm})$. PTE and PTM showed absorption bands at $419 \mathrm{~nm}(2.96 \mathrm{eV})$ and
$405 \mathrm{~nm}(3.06 \mathrm{eV})$, respectively. These results show that the effect of the electron donating methoxy group in PMOT increases the wavelength of maximum absorption of PMOT (bathochromic shift or red shift) when compared to PTE and PTM. The difference in the maximum absorption wavelengths between PTE (419 nm) and PTM (405 nm) can be related to two factors: (i) PTE has a more extensive 


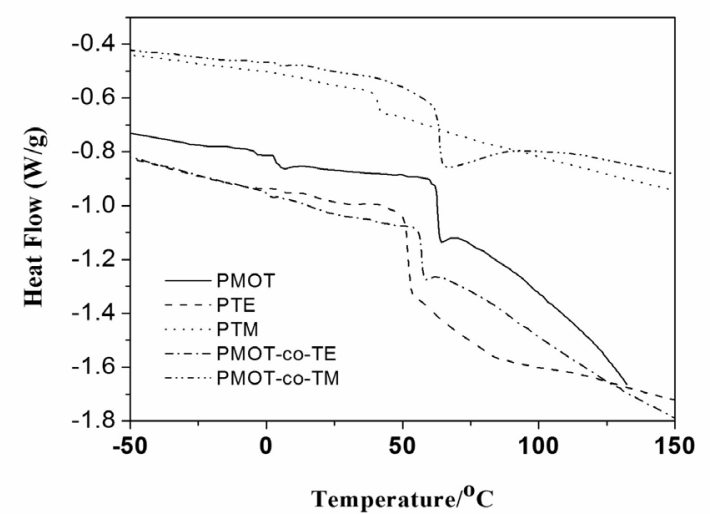

Figure 3. DSC curves of the polymers and copolymers.

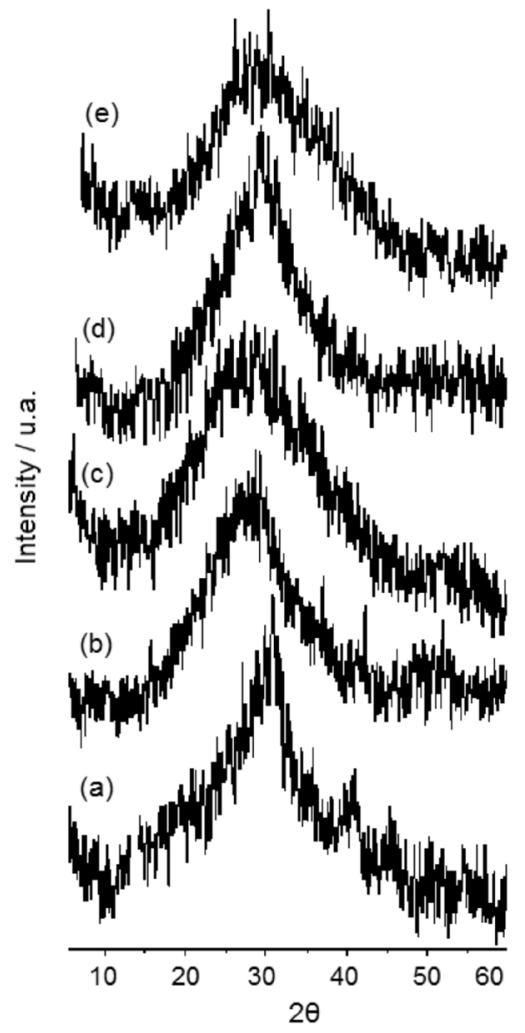

Figure 4. X-ray diffraction patterns of polymers and copolymers: (a) PMOT; (b) PTE; (c) PTM; (d) PMOT-co-TE; and (e) PMOT-co-TM.

Table 2. The TGA results and transition temperatures of the polymers and copolymers $\left(T_{d}\right.$ : initial temperature of degradation, $T_{t d}$ : temperature of total decomposition, $\mathrm{T}_{\mathrm{g}}$ : glass transition temperature)

\begin{tabular}{lcccc}
\hline Polymers & $\mathrm{T}_{\mathrm{d}}\left({ }^{\circ} \mathrm{C}\right)$ & Residue $(\%)$ & $\mathrm{T}_{\mathrm{td}}\left({ }^{\circ} \mathrm{C}\right)$ & $\mathrm{T}_{\mathrm{g}}\left({ }^{\circ} \mathrm{C}\right)$ \\
\hline PMOT & 145 & 32.2 & 726 & 62 \\
PTE & 200 & 2.4 & 547 & 48 \\
PTM & 230 & 5.9 & 519 & 41 \\
PMOT-co-TE & 175 & 6.3 & 536 & 56 \\
PMOT-co-TM & 200 & 6.6 & 474 & 59 \\
\hline
\end{tabular}

$\pi$-conjugated system than PTM, which implies a lower energy required for $\pi-\pi *$ transitions, and/or ( $i i)$ the ethanol group in PTE favors a more coplanar conformation, resulting in a decrease in the $\pi-\pi^{*}$ transition energy when compared to PTM. ${ }^{31}$ The copolymers obtained had maximum absorption $\left(\lambda_{\max }\right)$ values intermediate between those of their homopolymers. PMOT-co-TE showed a $\lambda_{\text {max }}$ at $429 \mathrm{~nm}(2.89 \mathrm{eV})$ and PMOT-co-TM showed a $\lambda_{\text {max }}$ at 424 $\mathrm{nm}(2.93 \mathrm{eV})$. The observation that PMOT-co-TE has a $\lambda_{\max }$ greater than the PMOT-co-TM one demonstrates that the substituent groups in the monomers TE and TM maintain their effect on the $\lambda_{\max }$ of copolymers.

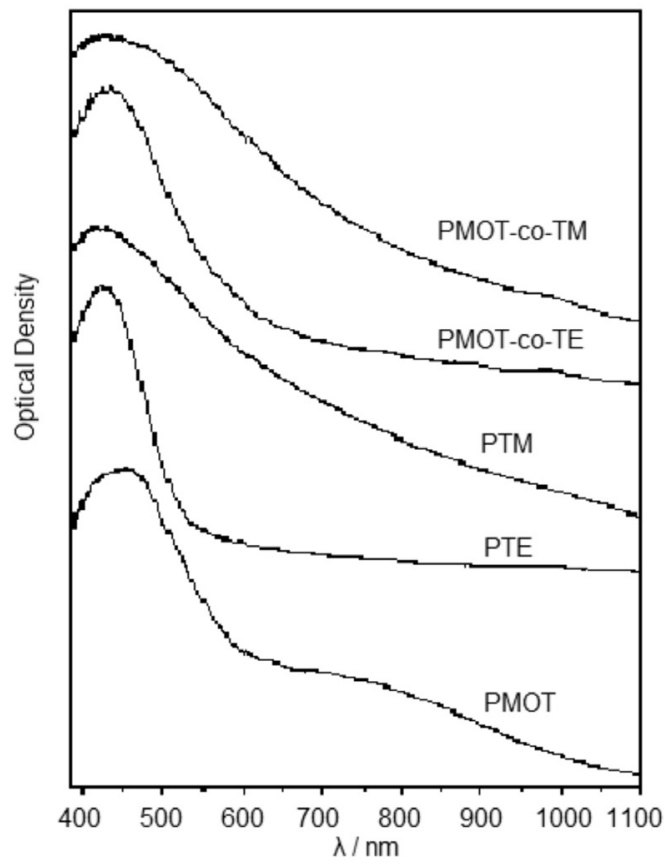

Figure 5. Absorption spectra in DMF as a function of wavelength for PMOT, PTM, PTE and their copolymers.

All polymers and copolymers obtained show an intense orange luminescence above $600 \mathrm{~nm}$ that is visible to the naked eye, as shown in Figure 6. The PL spectra of the materials obtained in this work are well resolved for the four transitions $\left(\mathrm{E}_{00}, \mathrm{E}_{01}, \mathrm{E}_{02}\right.$ and $\left.\mathrm{E}_{03}\right)$ due to their large size and good extension of conjugation, indicating the good structural quality of the materials. The variation of the substituent groups in homopolymers and copolymers did not significantly alter the first vibrational band $\left(\mathrm{E}_{01}\right), \lambda_{\max }$ ca. $613 \mathrm{~nm}$. All bands showed small changes in the emission intensity of the band with purely electronic transition $\left(\mathrm{E}_{00}\right)$ and of the second vibrational band $\left(\mathrm{E}_{02}\right)$. In PMOT, the $\mathrm{E}_{00}$ and $\mathrm{E}_{02}$ bands presented similar probabilities of transition (similar emission intensities). Compared with PTE, PMOT has a greater probability of transition from the $\mathrm{E}_{00}$ band and 
Table 3. Absorption and emission data for PMOT, PTE, PTM and their copolymers

\begin{tabular}{|c|c|c|c|c|c|}
\hline \multirow[t]{2}{*}{ Polymers } & \multicolumn{5}{|c|}{$\begin{array}{l}\text { Band } \\
\text { Absorption Emission }\end{array}$} \\
\hline & $\lambda_{\max }$ & $\mathrm{E}_{00}$ & $\mathrm{E}_{01}$ & $\mathrm{E}_{02}$ & $\mathrm{E}_{03}$ \\
\hline PMOT & $\begin{array}{l}452 \mathrm{~nm} \\
2.7 \mathrm{eV}\end{array}$ & $\begin{array}{l}561 \mathrm{~nm} \\
2.2 \mathrm{eV}\end{array}$ & $\begin{array}{l}613 \mathrm{~nm} \\
2.0 \mathrm{eV}\end{array}$ & $\begin{array}{l}673 \mathrm{~nm} \\
1.8 \mathrm{eV}\end{array}$ & $\begin{array}{r}748 \mathrm{~nm} \\
1.6 \mathrm{eV}\end{array}$ \\
\hline PTE & $\begin{array}{l}419 \mathrm{~nm} \\
2.9 \mathrm{eV}\end{array}$ & $\begin{array}{l}562 \mathrm{~nm} \\
2.2 \mathrm{eV}\end{array}$ & $\begin{array}{l}611 \mathrm{~nm} \\
2.0 \mathrm{eV}\end{array}$ & - & - \\
\hline PTM & $\begin{array}{l}405 \mathrm{~nm} \\
3.0 \mathrm{eV}\end{array}$ & $\begin{array}{l}566 \mathrm{~nm} \\
2.2 \mathrm{eV}\end{array}$ & $\begin{array}{l}614 \mathrm{~nm} \\
2.0 \mathrm{eV}\end{array}$ & $\begin{array}{l}673 \mathrm{~nm} \\
1.8 \mathrm{eV}\end{array}$ & $\begin{array}{l}753 \mathrm{~nm} \\
1.6 \mathrm{eV}\end{array}$ \\
\hline PMOT-co-TE & $\begin{array}{l}429 \mathrm{~nm} \\
2.8 \mathrm{eV}\end{array}$ & $\begin{array}{l}562 \mathrm{~nm} \\
2.2 \mathrm{eV}\end{array}$ & $\begin{array}{l}613 \mathrm{~nm} \\
2.0 \mathrm{eV}\end{array}$ & $\begin{array}{l}672 \mathrm{~nm} \\
1.8 \mathrm{eV}\end{array}$ & $\begin{array}{r}745 \mathrm{~nm} \\
1.6 \mathrm{eV}\end{array}$ \\
\hline PMOT-co-TM & $\begin{array}{l}424 \mathrm{~nm} \\
2.9 \mathrm{eV}\end{array}$ & $\begin{array}{l}563 \mathrm{~nm} \\
2.2 \mathrm{eV}\end{array}$ & $\begin{array}{l}614 \mathrm{~nm} \\
2.0 \mathrm{eV}\end{array}$ & $\begin{array}{l}675 \mathrm{~nm} \\
1.8 \mathrm{eV}\end{array}$ & $\begin{array}{l}748 \mathrm{~nm} \\
1.6 \mathrm{eV}\end{array}$ \\
\hline
\end{tabular}

a considerable decrease in emission from the $\mathrm{E}_{02}$ band. This behavior indicates that the $-\mathrm{CH}_{2}-\mathrm{CH}_{2}-\mathrm{OH}$ group favors the $\mathrm{E}_{00}$ band. This was confirmed by the PL spectrum for PMOT-co-TE, where the $\mathrm{E}_{00}$ band is more intense than the $\mathrm{E}_{02}$ band. The PTM showed behavior similar to its analog PTE: the emission intensity of the $\mathrm{E}_{00}$ band is more intense than that of the $\mathrm{E}_{02}$ band. In terms of the probability of transitions, PTE favors the $\mathrm{E}_{00}$ transition and disfavors the $\mathrm{E}_{02}$ transition. Despite the fact that PTM favors the $\mathrm{E}_{00}$ transition, the $\mathrm{E}_{02}$ transition also has an emission intensity very close to that of $\mathrm{E}_{00}$. Therefore, this observation suggests that the increasing of the size of the hydroxylated side chain can improve the $\mathrm{E}_{00}$ transition. This behavior may be linked to the different conformations assumed by the two homopolymers in solution. In the case of the copolymer PMOT-co-TM, the $\mathrm{E}_{02}$ band was more intense than the $\mathrm{E}_{00}$ band. This observation may be related to the two substituent groups that favor the two transitions almost equally, in which case the $\mathrm{E}_{02}$ band is more likely to occur than the $\mathrm{E}_{00}$ band.

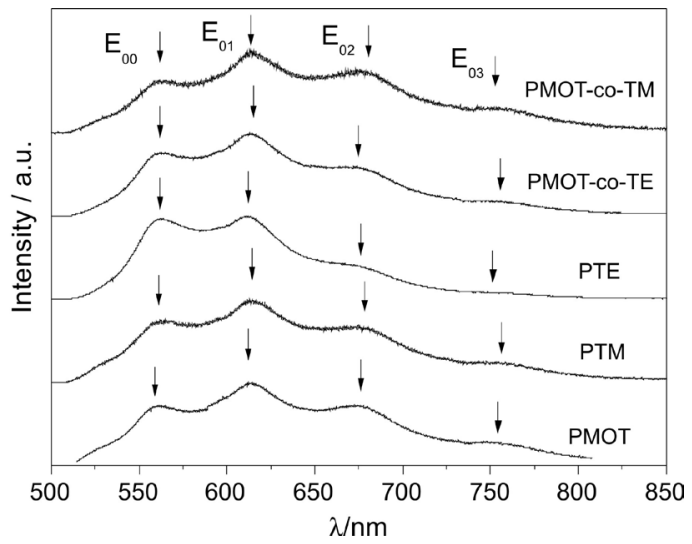

Figure 6. Photoluminescence spectra in DMF for PMOT, PTM, PTE and their copolymers. The labels $\mathrm{E}_{00}, \mathrm{E}_{01}, \mathrm{E}_{02}$ and $\mathrm{E}_{03}$ correspond to the pure electronic transition, the first, the second and the third vibronic bands, respectively.

\section{Conclusions}

This study compared the influence of different substituent groups on the final properties of thiophene homopolymers and copolymers. The polymerization method which was used it showed itself satisfactory with regard to the obtaining the desired materials at a shorter reaction time and with the material precipitation at the bottom of the own reaction system, with the advantage of not requiring any additional precipitating agent. The effect of alkoxy and hydroxyl substituents on conducting polymers was investigated. Although the TE and TM monomers present hydroxyl groups that could act as nucleophiles in the polymerization process resulting in materials with a low extension of conjugation, in this work, these materials presented interesting thermal and luminescent properties. Thus, all materials obtained showed good thermal stability and photoluminescence properties. The variation of the substituents in both the homopolymers and the copolymers did not significantly alter the $\lambda_{\max }$ of emission, but they caused interesting variations in the emission intensities of the $\mathrm{E}_{00}$ and $\mathrm{E}_{01}$ bands, which can be controlled by the appropriate choice of the substituent of the polymer chain. However, more detailed studies of the mechanism of emission of these materials are still needed for a better understanding of the photoluminescent properties, and future tests on the possibility of applications in polymer light emitting diodes (PLEDs) will be carried out.

\section{Supplementary Information}

Supplementary data, such as the images of the powders of the polymers studied and their corresponding solutions (Figure S1) and infrared spectra of the monomers and their corresponding polymers (Figures S2, S3 and S4) are available free of charge at http://jbcs.sbq.org.br, as PDF file. 


\section{Acknowledgments}

We thank FAPEMIG (CEX PPM III 0207/09; CEX APQ-01621-09; PRONEX EDT 479/07) and CNPq for their financial support. Special thanks are addressed to Prof. Glaura Goulart Silva, our colleague from the Chemistry Department who allowed us the use of the DSC and TG; thanks too to Prof. Luiz Alberto Cury and Dr. Marcelo Valadares, our colleagues from the Physics Department for the PL measurements.

\section{References}

1. Pang, Y.; Li, X.; Ding, H.; Shi, G.; Jin, L.; Electrochim. Acta 2007, 52, 6172 .

2. Hou, J.; Huo, L.; He, C.; Yang, C.; Li, Y.; Macromolecules 2006, 39, 594.

3. Liesa, F.; Ocampo, C.; Alemán, C.; Armelin, E.; Oliver, R.; Estrany, F.; J. Appl. Polym. Sci. 2006, 102, 1592.

4. Ocampo, C.; Armelin, E.; Liesa, F.; Alemán, C.; Ramis, X.; Iribarren, J. I.; Prog. Org. Coat. 2005, 53, 217.

5. Sotzing G. A.; Reynolds, J. R.; Steel, P.; Chem. Mater. 1996, 8,882 .

6. Li, F.; Albery, W. J.; J. Electroanal. Chem. 1991, 302, 279.

7. Roncali, J.; Chem. Rev. 1992, 92, 711.

8. Fouad, I.; Mechbal, Z.; Chane-Ching, K. I.; Adenier, A.; Maurel, F.; Aaron, J. J.; Vodicka, P.; Cernovska, K.; Kozmik, V.; Svoboda, J.; J. Mater. Chem. 2004, 14, 1711.

9. Ribeiro, A. S.; Jr, W. A. G.; Filho, P. F. S.; De Paoli, M. A.; Synth. Met. 2004, 145, 43.

10. Jang, S. Y.; Sotzing, G. A.; Macromolecules 2004, 37, 4351.

11. Chen, S. A.; Tsai, C. C.; Macromolecules 1993, 26, 2234.

12. Andersson, M. R.; Selse, D.; Berggren, M.; Jarvinen, H.; Hjertberg, T.; Inganas, O.; Wennerstrom, O.; Osterholm, J. E.; Macromolecules 1994, 27, 6503.

13. Bizzarri, P. C.; Andreani, F.; Casa, C. D.; Lanzi, M.; Salatelli, E.; Synth Met. 1995, 75, 141.

14. Hirota, N.; Hisamatsu, N.; Maeda, S.; Tsukahara, H.; Hyodo, K.; Synth. Met. 1996, 80, 67.
15. Hong, X.; Tyson, J. C.; Middlecoff, J. S.; Collard, D. M.; Macromolecules 1999, 32, 4232.

16. Ganapathy, H. S.; Kim, J. S.; Jin, S. H.; Gal, Y. S.; Lim, K. T.; Synth. Met. 2006, 156, 70.

17. Patrício, P. S. O.; Calado, H. D. R.; Oliveira, F. A. C.; Righi, A.; Neves, B. R. A.; Silva, G. G.; Cury, L.; J. Phys.: Condens. Matter 2006, 18, 7529.

18. Sotzing, G. A.; Reynolds, J. R.; Steel, P. J.; Chem. Mater. 1996, 8,882 .

19. Mert, O.; Sahin, E.; Ertas, E.; Ozturk, T.; Aydin, E. A.; Toppare, L.; J. Electroanal. Chem. 2006; 591, 53.

20. Alves, M. R. A.; Calado, H. D. R.; Donnicci, C. L.; Matencio, T.; Synth. Met. 2010, 160, 22.

21. Tang, H.; Zhou, Z.; Zhong, Y.; Liao, H.; Zhu, L.; Thin Solid Films 2006, 515, 2447.

22. Hu, X.; Xu, L.; Polymer 2000, 41, 9147.

23. Cihaner, A.; Onal, A. M.; J. Electroanal. Chem. 2007, 601, 68.

24. Daoust, G.; Leclerc, M.; Macromolecules 1991, 24, 455.

25. Dass, A.; Mulik, S.; Sotiriou-Leventis, C.; Leventis, N.; Synth. Met. 2006, 156, 966.

26. Welzel, H. P.; Kossmehl, G.; Boettcher, H.; Engelmann, G.; Hunnius, W. D.; Macromolecules 1997, 30, 7419.

27. Oliver, R.; Munoz, A.; Ocampo, C.; Alemán, C.; Armelin, E.; Estrany, F.; Chem. Phys. 2006, 328, 299.

28. Bundgaard, E.; Krebs, F. C.; Macromolecules 2006, 39, 2823.

29. Kontturi, K.; Pohjakallio, M.; Sundholm, G.; Vieil, E.; J. Electroanal. Chem. 1995, 384, 67.

30. Calado, H. D. R.; Matencio, T.; Donnici, C.L.; Cury, L. A.; Rieumont, J.; Pernaut, J.M.; Synth. Met. 2008, 158, 1037.

31. Philip, B.; Xie, J.; Chandrasekhar, A.; Abraham, J.; Varadan, V. K.; Smart Mater. Struct. 2004, 13, 295.

32. Pohjakallio, M.; Sundholm, G.; Talon, P.; J. Electroanal. Chem. 1996, 401, 200.

33. Wang, Y.; Rubner, M. F.; Buckley, L. J.; Synth. Met. 1991, 41, 1103.

Submitted: March 18, 2010

Published online: September 21, 2010 


\title{
Supplementary Information
}

\section{Synthesis and Characterization of New 3-Substituted Thiophene Copolymers}

\author{
Marcos R. A. Alves, ${ }^{*}$ Hállen D. R. Calado, Claudio L. Donnici and Tulio Matencio
}

Departamento de Química, ICEx/Universidade Federal de Minas Gerais, 31270-901 Belo

Horizonte-MG, Brazil

a)
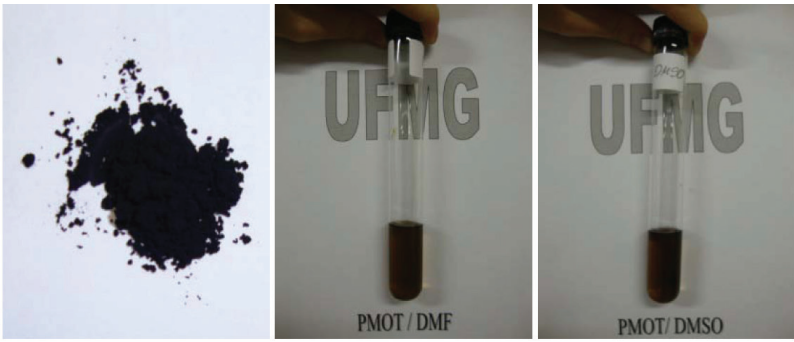

b)


c)
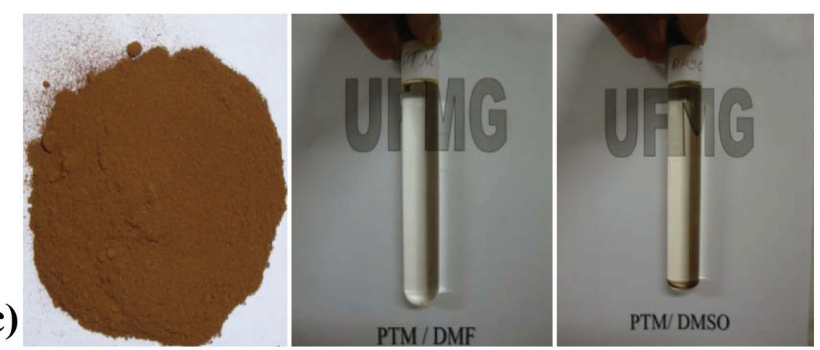

d)
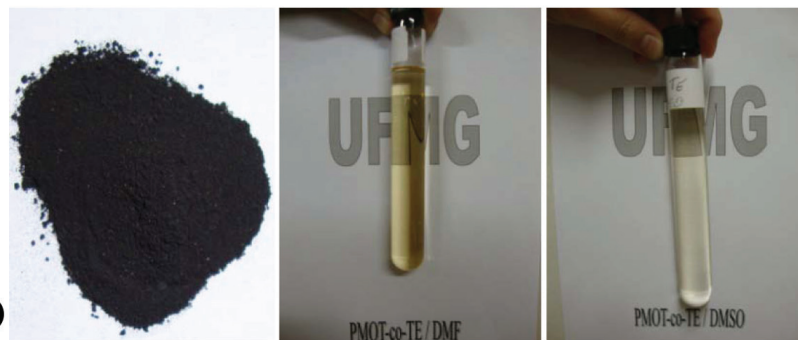

e)
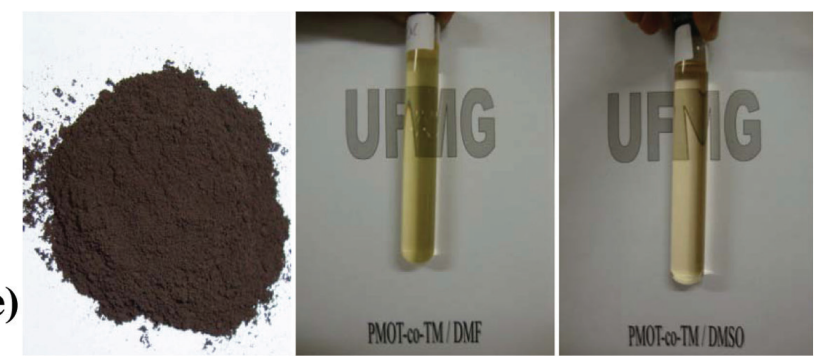

Figure S1. Images of the powders of the polymers and copolymers and their corresponding solutions in DMF and DMSO: a) PMOT/DMF and PMOT/ DMSO; b) PTE/DMF and PTE/DMSO; c) PTM/DMF and PTM/DMSO; d)PMOT-co-TE/DMF and PMOT-co-TE/DMSO; e)PMOT-co-TM/DMF and PMOT-co-TM/DMSO. PTM is poor soluble (only a small fraction, maybe with soluble oligomers, it is in solution). 


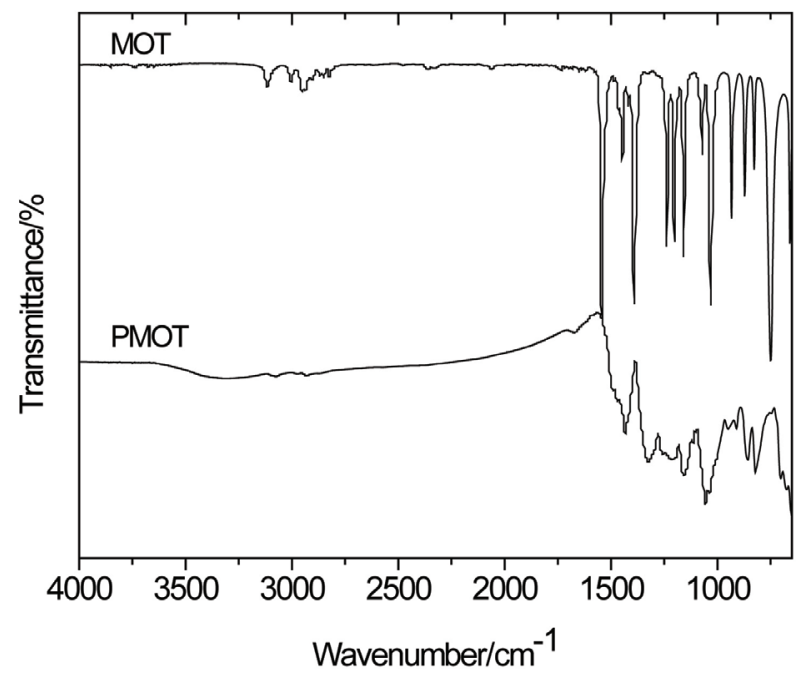

Figure S2. FT IR spectra of the monomer 3-methoxythiophene (MOT) and polymer poly(3-methoxythiophene) (PMOT).

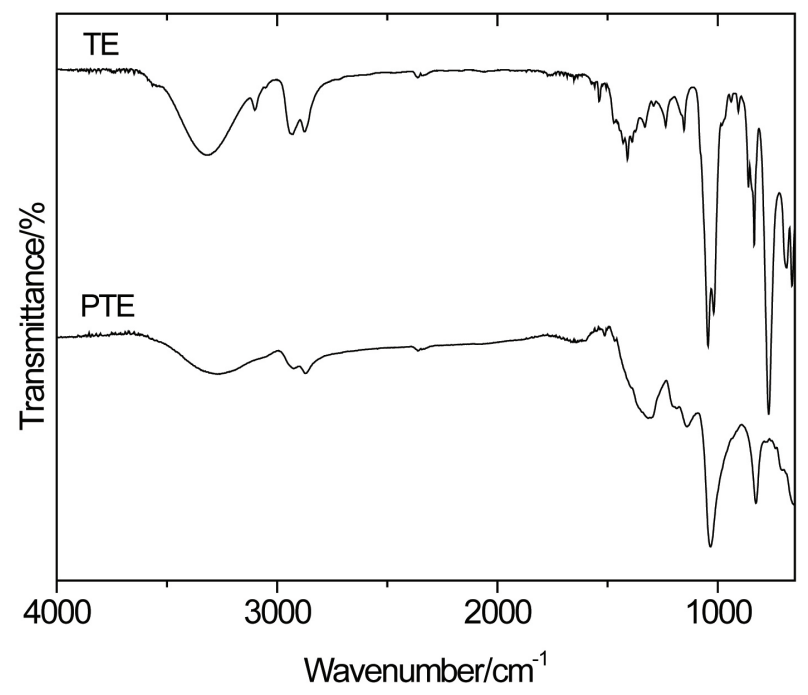

Figure S3. FT IR spectra of the monomer 3-thiopheneethanol (TE) and polymer poly(3-thiopheneethanol) (PTE).

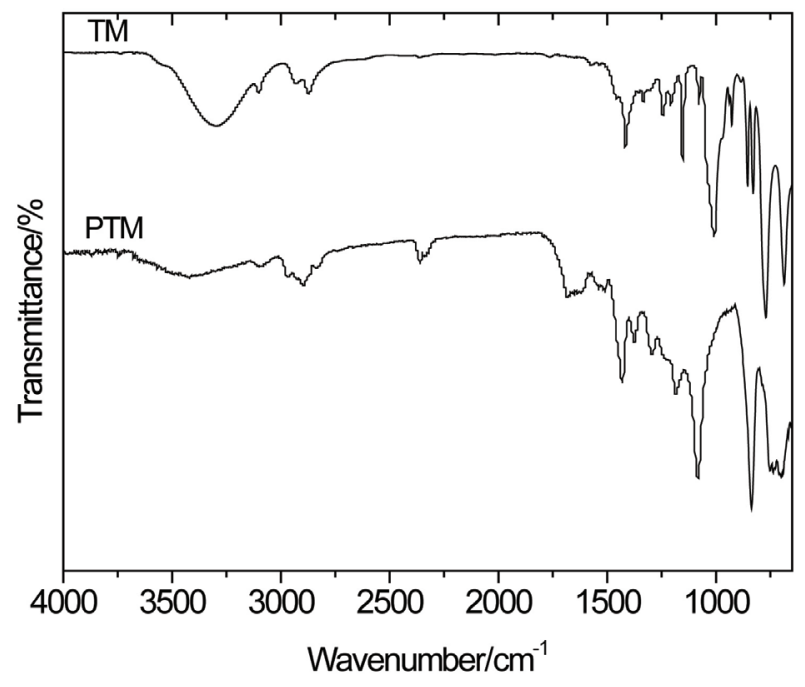

Figure S4. FT IR spectra of the monomer 3-thiophenemethanol (TM) and polymer poly(3-thiophenemethanol) (PTM). 